\title{
Effectiveness of Basic Body Awareness in Chronic Nonspecific Low Back Pain: A Case Study
}

\author{
Authors \\ Karishma Barot ${ }^{1 *}$, Vidhya Solanki ${ }^{2}$, Khatri $\mathrm{SM}^{3}$ \\ ${ }^{1,2}$ Tutor, ${ }^{3}$ Principal
}

Nootan College of Physiotherapy, Sankalchand Patel University, Visnagar, Gujarat, India 384315

*Corresponding Author

Karishma Barot

Email: karishma261993@gmail.com

\begin{abstract}
Non-specific low back pain does not have a known pathoanatomical cause. It affects humankind of all ages and is a leading benefactor to disease worry worldwide. In this case study, we describe the effectiveness of basic body awareness in terms of pain relief and improved functional aptitude in 22 year old male patient with non specific low backache. Further, we believe that basic body awareness therapy can be considered as one of the therapeutic option in the management of chronic nonspecific low back pain.
\end{abstract}

Keywords: physical therapy, basic body awareness, chronic non specific low back pain and phonophoresis.

\section{Introduction}

Basic body awareness therapy (BBAT) is an evidence-based treatment form in physiotherapy first developed in the $1970 .{ }^{1}$ Body awareness therapies can be defined as body-oriented physiotherapeutic advance using a integrated prospect in physiotherapy treatment directed towards an awareness of how the body is used, in terms of body function, behavior and interaction with self and others. ${ }^{2}$ BBAT aims to bring aspect of health and human resources to the forefront. The BBAT treatment modality was developed and described by the French psychoanalyst and dancer Dropsy $^{3,4}$ and the physiotherapist Roxendal ${ }^{5}$.

It has kindred in a number of different movement systems from Western and Eastern tradition (Alexander, Feldenkreis, Gindler, Idla, Zen meditation, T'ai chi) emphasizing the body and nonverbal communication as a gateway to personal empowerment. ${ }^{6}$ The prime goal of BBAT is to establish increased awareness of the body and consciousness in movements, progressing towards less effort and a better function in being, doing and relating. The therapy program includes motion from everyday life, lying, sitting, standing and walking. It also includes the use of vocalization relational exercises and massage. ${ }^{7}$ considering the beneficial effects of BBAT, We thought of finding out its effectiveness is chronic non specific low back pain. Have nonspecific low back pain does not have a known pathoanatomiacal cause. It affects inclusive of everyone and is a leading contributor to disease burden worldwide. 


\section{Case Study}

History: We describe a 22 year old male patient. His height was 158 centimeters, weight 59 kilograms and body mass index (BMI) was 23.6. The patient was seen by a physiotherapist and enrolled for daily treatment. He was referred for physiotherapy by a general practitioner and diagnosed as a case of non-specific low back. He complained of lower back pain and sometimes paresthesis or heaviness in both lower legs since three months. He never had history of similar pain in the past, heavy weight lifting or any trauma. He belonged to a middle socioeconomic class and fair family and social support. The patient reported having no other significant orthopedic issues.

Physical examination: His vital signs were normal. Postural findings showed increased lumbar lordosis and slight forward head posture. There was a moderate loss of cadence, and very limited locomotion at the hips during ambulation. Palpation revealed that there was mild tenderness around L5-S1, mild tightness of back extensors and hip flexors. Passive range of rotation to wither side was terminally restricted and bilateral active straight leg raising test was positive at 75 degree.

Procedure: Ethical approval was granted from the Institutional Ethical Committee and the patient gave an informed written consent. His demographic data, physical examination and visual analogue scale score were recorded. Basic body awareness exercises were first demonstrated to the patient and then supervised with use of verbal commands so that patient (figure 1) could perform it correctly for at least 10 minutes in standing. In addition to this, he was treated with phonophoresis with piroxicam ointment and aqua sonic gel with $1.25 \mathrm{w} / \mathrm{cm}^{2}$ for 5 minutes with 1 $\mathrm{MHz}$ pulsed mode ultrasound with 1:1 pulse ratio. He was advised to take rest, avoid strenuous activity, avoid lifting heavy weights, apply hot water fomentation and local analgesic ointment if required. After six weeks, his pain got reduced from 6.9 to 2.4 on visual analogue scale and patient-specific functional scale (PSFS) score got changed from 6.3 to 1.7

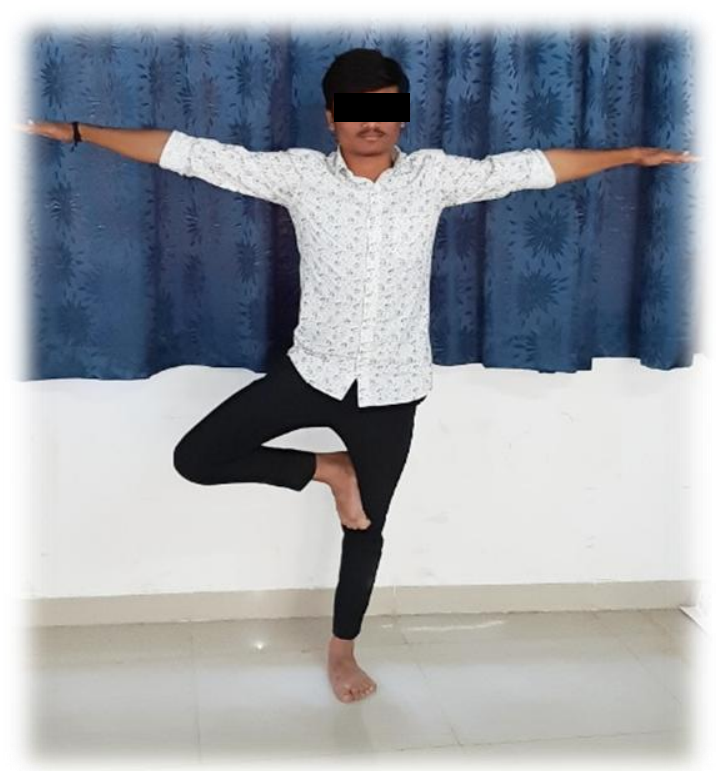

Figure1: Basic body awareness

\section{Discussion}

This case study provides information about the effectiveness of basic body awareness (BBA) in the treatment of chronic non specific low back pain. The term body awareness therapy was first used in the late 1960s in connection with physiotherapy for neurotic patients considering this fact; a 22 year old male patient with chronic nonspecific low back pain was selected as a study participant and evaluated after six weeks of BBA intervention. We found significant markdown in the symptoms of this patient.

This could be due to improved movement awareness, reduction in fear avoidance belief, facilitation of activities of daily living, improvement in mental health, placebo effect or psychological effect. ${ }^{8,9,10}$ However; in this study we are aware about the methodological limitations, difficulty in generalization and inability to study the cause and effect relationship.

\section{Conclusion}

Basic body awareness may be considered as an adjunct to conventional physiotherapy treatment in case of chronic nonspecific low back pain. 


\section{References}

1. Skattebo, Ulla-britt: Basic Body Awareness Therapy and Movement Sources Harmony. Oslo University College, 2005. ISBN 82-579-4468-8.

2. Gyllensten A. Basic body awareness therapy. Dissertation, Department of Physical Therapy Lund University, Lund, Sweden; 2002.

3. Dropsy J. The harmonious body (in Swedish). Stockholm: Natur och Kultur; 1988.

4. Dropsy J. Body attunement - the conditions for body use. In Bevegelseskvalitet - kunst o helse, Avdelningen for Helse- og sosialfag, Hogskolen i Bergen; 1999.

5. Roxendal G. Body awareness therapy and the body awareness scale, treatment an evaluation in psychiatric physiotherapy. Doctoral dissertation. Department of Rehabilitation Medicine, University of Goteborg and Psychiatric Department 2, Lillhagen Hospital, Hisings Backa, Go* teborg, Sweden, 1985.

6. Nettsted: www.hib.no Studier (Basic Body Awareness Methodology (BBAM) Studier - Hogskoleni Bergen)

7. https://en.wikipedia.org/w/index.php title Basic body awareness methodology and oldid 859461046.

8. Muhammad Nazim Farooq: Lower thoracic syndrome Pak J Med Sci 2017 Vol. 33 No. 3 767-769.

9. Geerse WK: Bilateral leg symptoms--the T10 syndrome Man Ther. 2012 Jun; 17(3):251-4. Epub 2011 Sep 22. doi: 10.1016/j.math.2011.08.003.

10. https://www.researchgate.net/publication/5 1670630 Bilateral leg symptoms-The T10 syndrome [accessed Nov 18 2018]. 